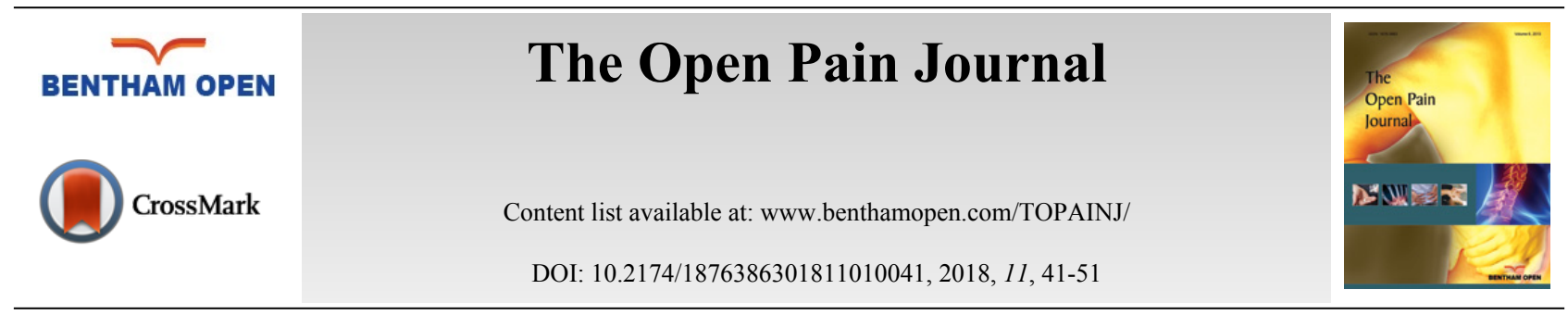

RESEARCH ARTICLE

\title{
An Experimental Investigation of the Effect of Age and Sex/Gender on Pain Sensitivity in Healthy Human Participants
}

\author{
Hanan El-Tumi ${ }^{1,2}$, Mark I. Johnson ${ }^{1}$ and Osama A. Tashani ${ }^{1,2, *}$ \\ ${ }^{I}$ Centre for Pain Research, School of Clinical and Applied Sciences, Leeds Beckett University, City Campus, Leeds LS1 \\ 3HE, United Kingdom \\ ${ }^{2}$ Department of Physiology, University of Benghazi, Benghazi, Libya
}

Received: April 24, 2018

Revised: November 9, 2018

Accepted: November 23, 2018

\begin{abstract}
:
Background:

Ageing is associated with alterations of the structure and function of somatosensory tissue that can impact on pain perception. The aim of this study was to investigate the relationship between age and pain sensitivity responses to noxious thermal and mechanical stimuli in healthy adults.

\section{Methods:}

56 unpaid volunteers ( 28 women) aged between 20 and 55 years were categorised according to age into one of seven possible groups. The following measurements were taken: thermal detection thresholds, heat pain threshold and tolerance using a TSA-II NeuroSensory Analyzer; pressure pain threshold using a handheld electronic pressure algometer; and cold pressor pain threshold, tolerance, intensity and unpleasantness.
\end{abstract}

\section{Results:}

There was a positive correlation between heat pain tolerance and age $(\mathrm{r}=0.228, \mathrm{P}=0.046)$, but no statistically significant differences between age groups for cold or warm detection thresholds, or heat pain threshold or tolerance. Forward regression found increasing age to be a predictor of increased pressure pain threshold $(B=0.378, P=0.002)$, and sex/gender to be a predictor of cold pressor pain tolerance, with women having lower tolerance than men $(\mathrm{B}=-0.332, \mathrm{P}=0.006)$.

\section{Conclusion:}

The findings of this experimental study provide further evidence that pressure pain threshold increases with age and that women have lower thresholds and tolerances to innocuous and noxious thermal stimuli.

\section{Significance:}

The findings demonstrate that variations in pain sensitivity response to experimental stimuli in adults vary according to stimulus modality, age and sex and gender.

Keywords: Heat Pain Threshold, Mechanical Stimuli, NeuroSensory Analyzer, Noxious Therma, Pain Sensitivity, Somatosensory.

\section{INTRODUCTION}

Ageing is associated with alterations in the structure and function of somatosensory tissue that can impact on pain perception in older and younger adults. Specifically, ageing is associated with reductions in neuronal numbers and

\footnotetext{
* Address correspondence to this author at the Centre for Pain Research, School of Clinical and Applied Sciences, Leeds Beckett University, City Campus, Leeds LS1 3HE, United Kingdom; Tel: 0044113812 3858; E-mail: O.Tashani@LeedsBeckett.ac.uk
} 
alterations in the expression and function of neurotransmitters, receptors, and glial cells, and this impairs the functioning of ascending (facilitatory) and descending (inhibitory) nociceptive modulatory transmission systems [1, 2].Hence, one would predict age-related changes in pain perception, even in the absence of pathology associated with injury and disease.

Reviews conducted over a decade ago suggested that sensitivity to noxious stimuli (i.e. pain sensitivity response) decreased in old age [2 - 4]. In 2017, we published a systematic review that found statistically significant differences in pain perception evoked by noxious stimuli between old and younger adults in seven of nine studies, but the direction of change was inconsistent [5]. Our meta-analysis provided tentative evidence of lower pressure pain thresholds in older compared with younger adults, but there were no differences in contact heat pain thresholds. We speculated that agerelated changes may depend on stimulus-modality and that ageing may differentially affect the functionality of different fibre types. We concluded that there was insufficient evidence to determine with confidence whether there are agerelated changes in pain sensitivity response between young and old healthy adults.

In the same year, Lautenbacher et al. published a systematic review and meta-analysis that provided evidence that ageing decreased sensitivity for low-intensity pain, especially in response to noxious heat stimuli and noxious stimuli applied to the head, but did not have a strong effect on pain tolerance [6]. The reviewers concluded, "Thus, after many years of investigating age-related changes in pain perception, we only have firm evidence that aging reduces pain sensitivity for lower pain intensities" (p104) [6].

There is a paucity of studies that have investigated age-related changes in pain perception in individuals without pre-existing injury or disease (i.e. healthy) exposed to noxious stimuli under experimental conditions (i.e. pain sensitivity response). Those that exist are conflicting and of low methodological quality. The aim of this study was to investigate the relationship between age and pain sensitivity response to noxious thermal and mechanical stimuli in healthy adults aged between 20 and 55 years. We decided to restrict the age categories to adults rather than children, adolescents, older adults or the elderly so that we could focus on age-related effects that would be less likely to have been affected by pathophysiology or comorbidities associated with old age [7,8]. Furthermore, there is strong research evidence to suggest that healthy women have lower pain thresholds and tolerances to noxious stimuli resulting from the influence of a wide variety of situational, physiological, psychological and social factors [9 - 11]. Thus, equal numbers of men and women were recruited.

\section{METHODS}

\subsection{Study Design}

An experimental study was designed that categorised participants according to age into one of seven possible groups based on the World Health Organisation (WHO) standard [12] as follows: 20 to $<25$ years; 25 to $<30$ years; 30 to $<35$ years; 35 to $<40$ years; 40 to $<45$ years; 45 to $<50$ years; and 50 to $<55$ years. There were equal numbers of men and women in each group. Procedures were in accordance with the 1964 Helsinki declaration and later amendments for ethical standards for studies using human participants. The study was approved by the research ethics committee at Leeds Beckett University, UK.

\subsection{Recruitment and Enrolment of Participants}

A convenience sample of 56 unpaid volunteers aged between 20 to 55 years was sought via advertisements in our university. Volunteers expressing interest received a participant information pack that included eligibility criteria. Volunteers were requested not to take part in the study if they did not consider themselves healthy, had a long-term illness, were currently seeking medical care, were experiencing pain or sensory disturbances, taking any medication, were known to be pregnant, or had a dermatological condition. There was no restriction on ethnicity nor body mass index although this was recorded. Volunteers were given $48 \mathrm{~h}$ to consider participation before a formal invitation to attend a study visit was made providing there was space in the relevant group allocation block. Volunteers were categorised according to age into one of the seven groups providing the group allocation was not full (i.e. using block randomisation) and invited to attend one study visit lasting no more than 90 minutes.

\subsection{Study Visit}

The study visit took place at our Pain Research Laboratory between 9am-midday. All the procedures were conducted by one female investigator who was fluent in English (35 years of age, Middle Eastern ethnicity). On arrival, 
volunteers were screened for eligibility, briefed about the experiment and familiarised with the equipment to be used. Volunteers were then enrolled onto the study by signing an informed consent form and reminded that they were free to withdraw at any time and without reason.

\subsection{Procedure}

Measurements of subjective response to various stimuli (i.e. quantitative sensory testing) were recorded whilst the participant was seated on a plinth in the following order; cold detection threshold, warm detection threshold, heat pain threshold, heat pain tolerance, blunt pressure pain threshold, cold pressor pain threshold, cold pressor pain tolerance, cold pressor pain intensity and cold pressor pain unpleasantness. Instructions for each test were read by the investigator from a crib sheet.

\subsubsection{Contact Thermal Stimuli}

Thresholds to contact thermal stimuli were measured using a TSA NeuroSensory Analyzer (Medoc, Ramat Yishai, Israel) using a protocol adapted from the recommendations of the German Research Network on Neuropathic Pain (DFNS) for standardized Quantitative Sensory Testing [13]. Stimuli were delivered using a square $30 \mathrm{x} 30 \mathrm{~mm}$ thermode placed on the surface of the skin at the thenar eminence of the dominant hand using the method of ascending limits for heat stimuli and descending limits for cold stimuli at a rate of $1{ }^{\circ} \mathrm{C} / \mathrm{sec}$ from the baseline value of $32^{\circ} \mathrm{C}$ (adaptation temperature) and a maximum temperature of $50.5^{\circ} \mathrm{C}$ [14]. Participants indicated task-related sensory events by pressing a response button held in their non-dominant hand. Each measurement was taken twice with 10 seconds rest between each repetition and the average of the two readings was calculated and used in subsequent analysis. There was at least a 10 seconds gap between different types of sensory measurement. Participants were instructed as follows:

- Cold detection threshold: "Please press the response button as soon as you feel the slightest change of temperature to 'cold'."

- Warm detection threshold: "Please press the response button as soon as you feel the slightest change of temperature to 'warm'."

- Heat pain threshold: "The temperature of the skin will increase to 'warm' and a few moments later to 'hot'. Eventually, a painful component will be added to the sensation of 'hot', and it may change in quality from 'hot' to, for example, 'burning' or 'stinging hot'. Please press the response button immediately at the first 'burning' or painful sensation."

- Heat pain tolerance: "The temperature of the skin will increase to 'warm' and a few moments later to 'hot'. Eventually, a painful component may be added to the sensation of 'hot', and it will change in quality from 'hot' to, for example, 'burning' or 'stinging hot'. Please press the response button immediately when this 'burning' or 'stinging hot' sensation becomes unbearably painful."

\subsubsection{Blunt Pressure Stimuli}

Pressure pain threshold was measured at the thenar eminence of the non-dominant hand using a handheld electronic pressure algometer (range $=0-2000 \mathrm{kPa}$, Somedic, Sweden) with a 1-cm diameter circular probe. The participant was seated with their hand supported by the hand of the investigator that rested on a table. The investigator pressed the algometer probe against the surface of the skin to apply pressure increasing at a constant rate of $10 \mathrm{kPa} / \mathrm{s}$ monitored by the in-device force application rate monitor. Participants were instructed to say 'Now!' as soon as the pressure started to be painful (i.e. 'the first sensation of pain'). Two measurements were taken with a 20 -second interval and the average used in subsequent analyses [15].

\subsubsection{Cold Pressor Stimuli}

Participants immersed their non-dominant hand in a warm water bath at $37^{\circ} \mathrm{C}$ for 3 minutes to standardise the skin temperature before transferring the hand into a bucket containing a slurry of ice-water at $1-2^{\circ} \mathrm{C}$ with their fingers spread apart. Participants were instructed to say the word 'Pain' when they experienced the ".... the first sensation of pain in the hand or fingers" and to keep their hand immersed in the iced-water until they "... [could] no longer tolerate the pain in the hand", at which point they should withdraw the hand from the iced-water. Cold pressor pain threshold was measured as the duration between immersing the hand in iced-water to 'Pain'. Cold pressor pain tolerance was measured as the duration between 'Pain' and hand withdrawal. Participants were instructed to withdraw their hand three 
minutes after 'pain' if they had not already done so and three minutes was recorded on the data sheet.

Participants rated cold pressor pain intensity on a $100 \mathrm{~mm}$ Visual Analogue Scale (VAS) immediately after withdrawing the hand from the iced-water in response to the instruction: "How painful was the stimulus just before withdrawing your hand from the iced water where zero equals the least pain imaginable and one hundred equals the worst possible pain imaginable." Cold pressor pain unpleasantness was rated immediately, after withdrawing the hand from the iced-water in response to the instruction: "How unpleasant was the stimulus just before withdrawing your hand from the iced-water where zero equals not unpleasant at all and one hundred equals the most unpleasant that I could imagine."

\subsection{Data Management and Analysis}

\subsubsection{Sample Size Calculation}

The sample size was calculated for heat pain threshold as a dependent variable and age as the independent variable using an online software calculator (https://www.ai-therapy.com/psychology-statistics/sample-size-calculator). A sample size calculation was conducted using alpha set at 0.05 , beta set at 0.90 and a correlation coefficient of 0.33 based on a previous study [16] resulting in a target of 52 participants. Therefore, a total of 56 participants were recruited in anticipation of some participants may drop out during the experimental procedures. All participants completed all requested procedures.

Data was analysed using descriptive statistics. Kolmogorov-Smirnov tests were used to examine normality of the distribution of data. Normally distributed data were expressed as mean and standard deviation and one-way ANOVAs used to compare more than two groups with Tukey's test used as a post hoc test for multiple comparisons. If a nonnormal distribution was found, data were log-transformed and tested again for normality. If normality was not obtained after log transformation, the data were tested using a Median test. Linear relationships between sensory testing data (dependent variables) with age, sex, and body mass index (independent variables) were assessed using stepwise linear regression using the forward elimination model (i.e. forward regression), with alpha set at 0.05 . A correlation coefficient of $\geq 0.2$ and a p-value $<0.05$ signified a strong significant relationship. All statistical analyses were conducted using SPSS version 22 (IBM) Armonk, New York, USA, for Windows.

\section{RESULTS}

\subsection{Characteristics of Study Sample}

Fifty-six individuals were enrolled in the study and all completed the experiment (mean \pm Standard Deviation (SD) age $=37.3 \pm 10.5$ years, 28 women, Supporting Information, Appendix 1). There was no statistically significant difference in age between men and women (mean \pm SD difference in age $=0.321$ years, $\mathrm{n}=56, \mathrm{P}=0.9$, unpaired t-test). Men were heavier and taller than women but there were no statistically significant differences in Body Mass Index (BMI). There were no statistically significant differences in weight and height across age groups (Supporting Information, Appendix 2). There was a statistically significant difference in BMI across age groups with mean $\pm \mathrm{SD}$ BMI being higher in older age groups.

The Kolmogorov-Smirnov test discovered non-normal distributions for the cold detection threshold, warm detection threshold, cold pressor pain tolerance, and pain intensity (cold pressor task), therefore, raw data was log transformed prior to analysis and was found to be normally distributed.

\subsection{Contact Thermal Sensations}

\subsubsection{Cold Detection Threshold}

There were no differences in cold detection thresholds between age groups $(\mathrm{P}=0.67$, Table $\mathbf{1})$.

Table 1. Mean \pm standard deviation sensory test measurements across age groups.

\begin{tabular}{|c|c|c|c|c|c|c|c|c|c|}
\hline \multirow[t]{2}{*}{ Pain and Sensory Measurement } & \multicolumn{7}{|c|}{ Age Group (years, $n=8$ in each group) } & \multirow[t]{2}{*}{$\mathbf{F}$} & \multirow[t]{2}{*}{ P value } \\
\hline & $20<25$ & $25<30$ & $30<35$ & $35<40$ & $40<45$ & $45<50$ & $50<55$ & & \\
\hline Cold detection threshold $\left({ }^{\circ} \mathrm{C}\right)$ & $28.4 \pm 1.1$ & $28 \pm 1.6$ & $28.4 \pm 0.7$ & $27.8 \pm 0.9$ & $27.4 \pm 0.7$ & $27.5 \pm 1.8$ & $27.5 \pm 2.6$ & 0.69 & 0.67 \\
\hline Warm detection threshold $\left({ }^{\circ} \mathrm{C}\right)$ & $31.98 \pm 1.1$ & $32.5 \pm 1.8$ & $32.25 \pm 1.1$ & $32.75 \pm 1.6$ & $32.7 \pm 1$ & $33.2 \pm 2.7$ & $32.2 \pm 1.3$ & 0.47 & 0.82 \\
\hline
\end{tabular}


(Table 1) contd.....

\begin{tabular}{|c|c|c|c|c|c|c|c|c|c|}
\hline \multirow[t]{2}{*}{ Pain and Sensory Measurement } & \multicolumn{7}{|c|}{ Age Group (years, $n=8$ in each group) } & \multirow[t]{2}{*}{$\mathbf{F}$} & \multirow[t]{2}{*}{ P value } \\
\hline & $20<25$ & $25<30$ & $30<35$ & $35<40$ & $40<45$ & $45<50$ & $50<55$ & & \\
\hline Heat pain threshold $\left({ }^{\circ} \mathrm{C}\right)$ & $41.5 \pm 2.9$ & $40.7 \pm 4$ & $42.6 \pm 3.7$ & $42 \pm 5.8$ & $43 \pm 3.3$ & $42.85 \pm 5.2$ & $43.5 \pm 3$ & 0.45 & 0.85 \\
\hline Heat pain tolerance $\left({ }^{\circ} \mathrm{C}\right)$ & $47.5 \pm 1.76$ & $47.6 \pm 2.4$ & $48.35 \pm 1.9$ & $47 \pm 3$ & $48.55 \pm 1$ & $49 \pm 1.8$ & $48.3 \pm 1.5$ & 0.89 & 0.51 \\
\hline Pressure pain threshold $(\mathrm{KPa})$ & $367.3 \pm 211.7$ & $604.8 \pm 290.9$ & $690.5 \pm 321.6$ & $646.8 \pm 392.2$ & $783.9 \pm 300.97$ & $698.6 \pm 196.8$ & $787.2 \pm 178.4$ & 2.10 & 0.07 \\
\hline Cold pressor pain threshold (s) & $10.75 \pm 3.8$ & $9.1 \pm 5.8$ & $10.9 \pm 5.4$ & $12.9 \pm 10.6$ & $12.1 \pm 3.8$ & $9.25 \pm 3.8$ & $9.6 \pm 3.6$ & 0.51 & 0.80 \\
\hline Cold pressor pain tolerance (s) & $48.25 \pm 29.3$ & $38.75 \pm 57.5$ & $29.4 \pm 9.6$ & $60.1 \pm 73$ & $35.4 \pm 15.2$ & $40.5 \pm 21.5$ & $61.6 \pm 73.6$ & 0.54 & 0.77 \\
\hline $\begin{array}{c}\text { Cold pressor pain intensity }(100 \mathrm{~mm} \\
\text { VAS })\end{array}$ & $65 \pm 20$ & $76 \pm 15$ & $55 \pm 18$ & $67 \pm 26$ & $77 \pm 07$ & $76 \pm 21$ & $60 \pm 30$ & 1.44 & 0.22 \\
\hline $\begin{array}{l}\text { Cold pressor pain unpleasantness } \\
(100 \mathrm{~mm} \text { VAS })\end{array}$ & $81 \pm 11$ & $74 \pm 22$ & $68 \pm 23$ & $68 \pm 23$ & $75 \pm 11$ & $75 \pm 09$ & $62 \pm 31$ & 0.79 & 0.58 \\
\hline
\end{tabular}

$P$ values were calculated using one-way ANOVA across groups, ${ }^{*}$ statistically significant at $P<0.05$

Women detected changes to cold at higher temperatures than men suggesting that women were more sensitive, to changes to cold temperature $(\mathrm{P}=0.03$, Table 2, Supporting Information, Appendix 3). Forward regression revealed that sex was the predictor of cold detection threshold with a strong positive relationship $(\mathrm{B}=0.286, \mathrm{P}=0.016$, Table $\mathbf{3})$ suggesting that women were significantly more sensitive to decreasing cold temperature than men. There was also a statistically significant negative correlation between BMI and cold detection threshold ( $\mathrm{r}=-0.227, \mathrm{P}=0.046$, Pearson's correlation coefficient) suggesting that participants with higher BMI were more sensitive to changes to cold temperature.

Table 2 . Mean $\underline{ \pm}$ standard deviation sensory test measurements between women and men.

\begin{tabular}{|c|c|c|c|c|}
\hline Pain and Sensory Measurement & All $(n=56)$ & $\operatorname{Men}(n=28)$ & Women $(n=28)$ & P value \\
\hline Cold detection threshold $\left({ }^{\circ} \mathrm{C}\right)$ & $27.9 \pm 1.5$ & $27.5 \pm 1.7$ & $28.3 \pm 1$ & $\mathbf{0 . 0 3}^{\# *}$ \\
\hline Warm detection threshold $\left({ }^{\circ} \mathrm{C}\right)$ & $32.5 \pm 1.6$ & $32.9 \pm 1.8$ & $32.1 \pm 1.2$ & $0.04^{\# *}$ \\
\hline Heat pain threshold $\left({ }^{\circ} \mathrm{C}\right)$ & $42.3 \pm 4$ & $42.6 \pm 4.8$ & $42.1 \pm 3$ & 0.60 \\
\hline Heat pain tolerance $\left({ }^{\circ} \mathrm{C}\right)$ & $48.07 \pm 2$ & $48.7 \pm 1.5$ & $47.5 \pm 2.3$ & $0.02 *$ \\
\hline Pressure pain threshold $(\mathrm{KPa})$ & $653.5 \pm 295.4$ & $681.96 \pm 317$ & $624 \pm 273.9$ & 0.47 \\
\hline Cold pressor pain threshold (s) & $10.7 \pm 5.6$ & $11.5 \pm 6.9$ & $9.8 \pm 3.9$ & 0.27 \\
\hline Cold pressor pain tolerance (s) & $44.9 \pm 16.1$ & $60 \pm 19.9$ & $29.7 \pm 16.6$ & $0.01^{\# *}$ \\
\hline Cold pressor pain intensity (100mm VAS) & $6.8 \pm 2.1$ & $6.5 \pm 2.4$ & $7.1 \pm 1.8$ & $0.27^{\#}$ \\
\hline Cold pressor pain unpleasantness (100mm VAS) & $7.2 \pm 2$ & $6.9 \pm 2.4$ & $7.5 \pm 1.4$ & 0.27 \\
\hline
\end{tabular}

$P$ values for women $v s$. men were calculated using independent t-tests.

\# $\log$ transformation of data failed to produce normality and Mann-Whitney Test used.

*statistically significant at $P<0.05$

Table 3. Forward stepwise regression of sensory test measurements $(n=56)$.

\begin{tabular}{|c|c|c|c|c|c|c|}
\hline Pain and Sensory Measurement & Predictor & B & $\mathbf{t}$ & $\mathbf{R}^{2 \mathrm{c}}$ & $\mathbf{F}$ & P value \\
\hline Cold detection threshold $\left({ }^{\circ} \mathrm{C}\right)$ & Sex/Gender ${ }^{a}$ & 0.286 & 2.195 & 0.082 & 4.82 & 0.016 \\
\hline Warm detection threshold $\left({ }^{\circ} \mathrm{C}\right)$ & Sex/Gender ${ }^{a}$ & -0.226 & -2.024 & 0.071 & 4.10 & 0.024 \\
\hline Heat pain threshold $\left({ }^{\circ} \mathrm{C}\right)$ & BMI $^{\text {b }}$ & 0.374 & 2.965 & 0.140 & 8.79 & 0.002 \\
\hline \multirow{2}{*}{ Heat pain tolerance $\left({ }^{\circ} \mathrm{C}\right)$} & BMI $^{\mathbf{b}}$ & 0.361 & 2.841 & 0.130 & 8.07 & 0.003 \\
\hline & Sex/Gender ${ }^{a}$ & -0.310 & -2.341 & 0.212 & 5.48 & 0.010 \\
\hline Pressure pain threshold $(\mathrm{kPa})$ & Age & 0.378 & 2.974 & 0.143 & 8.85 & 0.002 \\
\hline Cold pressor pain threshold (s) & None & & & & & \\
\hline Cold pressor pain tolerance (s) & Sex/Gender ${ }^{a}$ & -0.332 & -2.585 & 0.110 & 6.68 & 0.006 \\
\hline Cold pressor pain intensity (100mm VAS) & None & & & & & \\
\hline Cold pressor pain unpleasantness (100mm VAS) & None & & & & & \\
\hline
\end{tabular}

${ }^{\mathrm{a}}$ Positive B indicates that men are associated with a higher value for the sensory test (dependent variable) and negative B indicates that women are associated with a lower value for the sensory test (dependent variable).

${ }^{\mathrm{b}}$ Positive B indicates that a higher predictor value is associated with a higher value for the sensory test (dependent variable) and negative B indicates that a higher predictor value is associated with a lower value for the sensory test (dependent variable).

${ }^{\mathrm{c}} \mathrm{R}^{2}$ indicates the proportion of variance in the sensory test (dependent variable) explained by the predicator variable (independent variable).

* Statistically significant at $P<0.05$. 


\subsubsection{Warm Detection Threshold}

There were no differences in warm detection thresholds between age groups $(p=0.82$, Table $\mathbf{1})$.

The warm detection threshold was lower for women than men suggesting that women were more sensitive to changes to warm temperature than men $(\mathrm{P}=0.04$, Table 2, Supporting Information, Appendix 4). Forward regression revealed that sex was the predictor of warm detection threshold with a strong negative relationship $(\mathrm{B}=-0.226, \mathrm{P}=$ 0.024 , Table 3) suggesting that women were more sensitive to increasing warmth than men.

\subsubsection{Heat Pain Threshold}

There were no differences in heat pain threshold between age groups $(\mathrm{P}=0.85$, Table $\mathbf{1})$ or between men and women ( $\mathrm{P}=0.6$, Table 2). Forward regression revealed that BMI was a predictor of heat pain threshold with a strong positive relationship $(\mathrm{B}=0.374, \mathrm{P}=0.002$, Table 3$)$ indicating that individuals with higher BMI had higher pain thresholds. This suggests that participants with higher BMI were less sensitive to noxious heat stimuli.

\subsubsection{Heat Pain Tolerance}

There were no differences in heat pain tolerance between age groups $(\mathrm{P}=0.51$, Table 1$)$, although there was a positive correlation between heat pain tolerance and age $(\mathrm{r}=0.228, \mathrm{P}=0.046$, Pearson coefficient). This suggests that pain tolerance increased with age. Heat pain tolerance was higher in men than women $(\mathrm{P}=0.02$, Table 2, Supporting Information, Appendix 5). Forward regression revealed that sex and BMI were predictors of heat pain tolerance with a strong negative relationship with sex $(B=0.31, p=-0.01$, Table 3). This indicates that men had higher heat pain tolerance than women. There was a strong positive relationship with BMI $(\mathrm{B}=0.361, \mathrm{P}=0.003$, Table 3$)$ indicating that participants with higher BMI had higher heat pain tolerance. This suggests that participants who were men or had higher BMI were less sensitive to noxious heat stimuli.

\subsubsection{Pressure Pain Threshold}

There were no differences in pressure pain threshold between age groups $(\mathrm{P}=0.07$, Table 1$)$ or between men and women $(\mathrm{P}=0.47$, Table 2$)$. Forward regression revealed that age was a predictor of pressure pain threshold with a strong positive relationship indicating that pressure pain threshold increased with age $((\mathrm{B}=0.378, \mathrm{P}=0.002$, Table $\mathbf{3}$, Fig. 1). This suggests that sensitivity to pressure pain decreases with age.

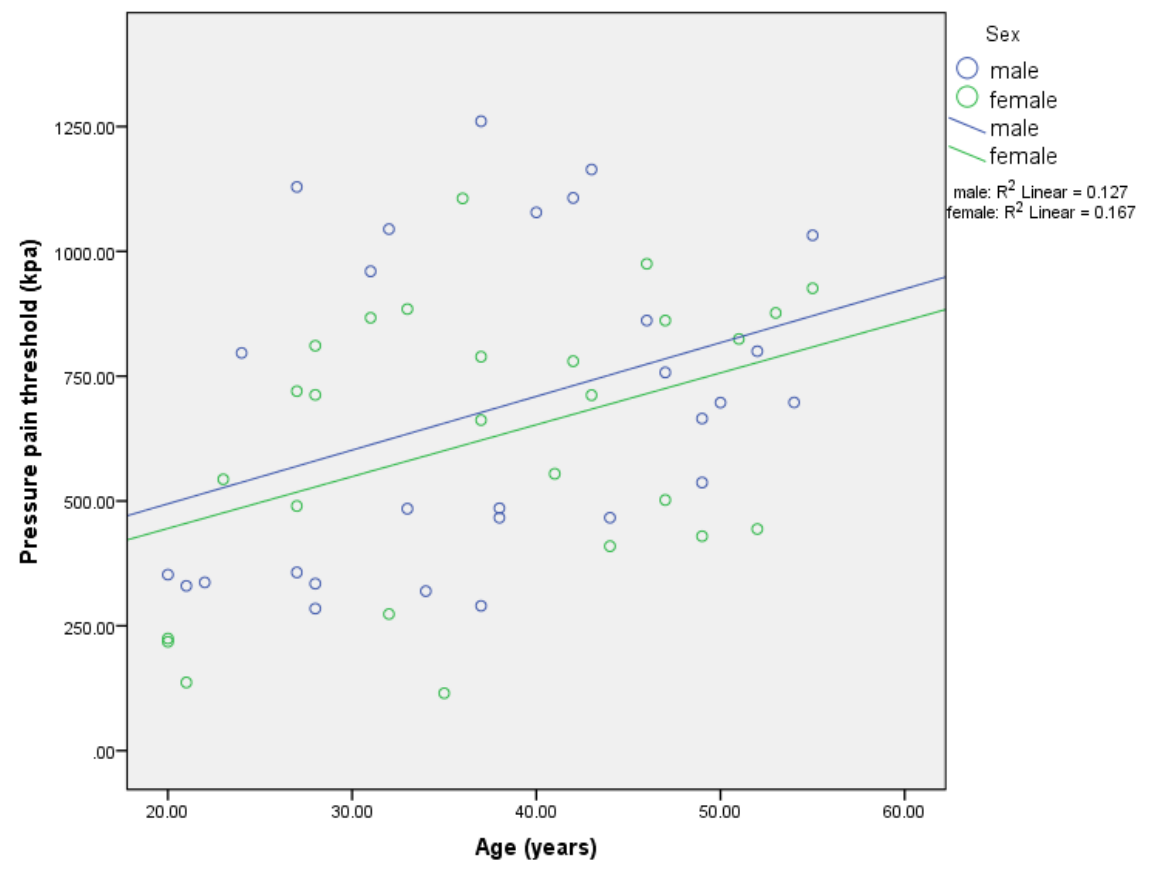

Fig. (1). Mean pressure pain threshold $(\mathrm{kPa})$ against age (years) for men and women. 


\subsubsection{Cold Pressor Pain}

\subsubsection{Cold Pressor Pain Threshold}

There were no differences in cold pressor pain threshold between age groups $(\mathrm{P}=0.8)$ or between men and women $(\mathrm{P}=0.27)$. Forward regression revealed no statistically significant relationships between cold pressor pain threshold and age, sex, or BMI (Table 3).

\subsubsection{Cold Pressor Pain Tolerance}

There were no differences in cold pressor pain tolerance between age groups $(\mathrm{P}=0.77$, Table 1). Cold pressor pain tolerance was higher for men than women $(\mathrm{P}=0.01$, Supporting Information, Appendix 6). Forward regression revealed that sex was a predictor of cold pressor pain tolerance with a strong positive relationship $(\mathrm{B}=-0.332, \mathrm{P}=0.006$, Table 3) indicating that cold pressor pain tolerance was higher in men.

\subsubsection{Cold Pressor Pain Intensity}

There were no differences in cold pressor pain intensity between age groups $(\mathrm{P}=0.22$, Table $\mathbf{1})$ or between men and women ( $\mathrm{P}=0.27$, Table 2 ). Forward regression revealed no statistically significant relationships between cold pressor pain intensity and age, sex, or BMI (Table 3 ).

\subsubsection{Cold Pressor Pain Unpleasantness}

There were no differences in cold pressor pain unpleasantness between age groups $(\mathrm{P}=0.58$, Table 1) or between men and women $(\mathrm{P}=0.27$, Table 2$)$. Forward regression analysis revealed no statistically significant relationships between cold pressor pain unpleasantness and age, sex, or BMI (Table 3).

\section{DISCUSSION}

This study found that sensitivity to noxious blunt pressure stimuli decreased (i.e. increasing pressure pain threshold) with increasing age in healthy individuals between 20 and 55 years of age, with $14 \%$ of the variation in pressure pain threshold measurements explained by variations in age. There was tentative evidence that heat pain tolerance increased with age. There were no statistically significant relationships between ageing and heat pain threshold, cold pressor pain, or detection of non-painful warmth or cold. This study found that healthy women had lower heat pain tolerance and cold pressor pain tolerance than men. There were no sex/gender differences for pressure pain threshold, heat pain threshold, cold pressor pain threshold, intensity or unpleasantness. Women were more sensitive to changes in nonpainful warmth or cold than men. There was no significant interaction between age and sex in any of the pain sensitivity measurements. This study found that healthy individuals with higher BMI were less sensitive to noxious heat (i.e. higher heat pain threshold and tolerance) but there were no statistically significant relationships between BMI and cold pressor pain. Healthy individuals with higher BMI were more sensitive to changes in non-painful cold but not warmth.

\subsection{Age-Related Pain Sensitivity Response}

Previously, we conducted a systematic review with meta-analysis of 12 studies, of which nine studies were specifically on adults, that found that the direction of change of statistically significant differences in pain sensitivity response between old (mean $\pm \mathrm{SD}=62.2 \pm 3.4$ to $79 \pm 4$ years) and younger adults $(22 \pm 1.5$ to $39.1 \pm 8.8$ years $)$ was inconsistent [5]. We concluded that there was tentative evidence that old adults may be more sensitive to mechanicallyevoked pain but not heat-evoked pain than young adults. Subsequently, a systematic review of 31 studies by Lautenbacher et al. [6] included a meta-analysis that found that pain threshold irrespective of stimulus modalities was higher in individuals $>60$ years $(n=1354$ older adults; 724 women) compared to younger adults $(\mathrm{n}=1558$ young adults; 771 women). Lautenbacher et al. also found that pain tolerance irrespective of stimulus modality was unaffected by age, although adults $>60$ years $(n=5601 ; 3290$ women) may have slight tendency toward reduced pressure pain tolerance ( $\mathrm{n}=5694$ young adults; 3623 women).

\subsubsection{Age-Related Changes in Pain Threshold}

The present study on a sample of participants between 20 and 55 years of age found that pressure pain threshold was higher as age increased. Interestingly, our previously published meta-analysis that pooled data of four studies (180 participants; 98 women) found that pressure pain threshold was lower in old adults (mean $\pm \mathrm{SD}=62.2 \pm 3.4$ to $79 \pm 4$ 
years) when compared with young adults $(22 \pm 1.5$ to $39.1 \pm 8.8$ years $)[5,6]$. High statistical and experimental heterogeneity undermined confidence in the finding of our meta-analysis. The meta-analysis by Lautenbacher et al. [6] of 12 studies (609 old versus 534 young participants) found no age-related effects on pressure pain threshold. When taken together the findings of these meta-analyses highlight continued uncertainty about the direction of age-related changes in pain sensitivity response to pressure algometry in healthy individuals. The differences in the results of primary studies may be due in part to differences and inconsistencies in cut points used to categorise old versus young age groups. For example, Herr et al. [17] found no differences in pain threshold between 86 younger adults (25-55 years) and 89 older adults (65-94 years), whereas Cole et al. [18] found pain threshold to be higher in 15 younger adults (mean \pm SD $26 \pm 3$ years) compared with 15 older adults (79 \pm 4 years). The mean difference of age in the studies selected for the meta-analysis by Lautenbacher et al. was very wide and ranged from 27.3 to 60.0 years.

Our finding in the present study of no age-related changes in pain threshold to contact heat or to cold pressor pain is consistent with our previous meta-analysis of five studies (355 participants; 172 men and 183 women) that found no differences in heat pain thresholds between old and younger adults [5]. In contrast, the meta-analysis by Lautenbacher et al. [6] of 16 studies (1045 old versus 845 young participants) found that old adults had higher heat pain threshold (especially delivered via contact-thermode or radiation) when compared with young adults, and suggested that older adults have reduced sensitivity to noxious thermal stimuli. An exploratory analysis by Lautenbacher et al. [6] suggested that age-related changes in pain threshold depended on the modality of the noxious stimuli, with age-dependent increases in pain thresholds occurring for older adults exposed to noxious heat stimuli but not noxious electrical and pressure stimuli. They concluded that stimulus modality had a substantial effect on age-related pain sensitivity response. Synthesising the findings of the present study with the two previously published meta-analysis suggests that, as far as pain threshold is concerned, there is no consistency in the findings of experimental studies to date.

\subsubsection{Age-Related Changes in Pain Tolerance}

We found that contact heat pain tolerance increased with age suggesting that older adults had reduced tolerance to noxious thermal stimuli but we found no age related-changes in cold pressor pain tolerance. The meta-analysis by Lautenbacher et al. [6] found age-related changes in pain tolerance to a variety of stimuli, although there was a tendency for individuals $>60$ years to have reduced pressure pain tolerance thresholds. Unfortunately, we did not measure pressure pain tolerance in our present study because this could have affected the response to other pain induction techniques we used. Synthesising the findings of the present study with the two previously published metaanalysis suggests that there is no consistency in the findings of studies investigating age-related changes in tolerance to noxious stimuli to date.

Overall, it seems logical from a physiological perspective to expect age-related changes in perceptual thresholds and tolerances in response to noxious stimuli, especially in older adults. Ageing is accompanied by a widespread and considerable alteration in the anatomy, biochemistry and functioning of neural and non-neural tissue [2]. There are agerelated structural changes in brain regions associated with processing noxious input and pain perception reduction [8] with reduced functioning of endogenous pain inhibitory processes [18, 19]. This is accompanied by a marked increase in the number of degenerated sensory fibres with signs of damage or degeneration, and this could be the reason for decreased pain sensitivity with advanced age. Variability in the type and nature of physiological and structural changes in the nervous tissues because of ageing might be the reason for the unpredictable pain sensitivity response to different pain induction techniques [20]. It also seems plausible that inconsistency in the findings of primary studies may reflect 'experimental noise' due to inadequacies and/or inconsistency in study methodology. Variables that may increase noise in study data be related to situation, context and design of the experiment including: laboratory setting; participant briefing and task instructions; the investigator's sex, age, ethnicity and appearance; cut points used to categorise older and younger participants; sample sizes; the type, location and method of delivering of stimuli; and timing and procedures to measure outcomes.

\subsection{Sex/Gender-Related Pain Sensitivity Response}

The present study found that women had lower tolerance to heat pain and cold pressor pain compared with men and this finding is consistent with substantial evidence from previous studies [9]. However, we found no differences in pain threshold for any of the noxious stimuli used (i.e. pressure, contact heat or cold pressor), and this is not consistent with previous studies by ourselves or others that have found that women have lower pain thresholds than men [16, 21]. We calculated sample size based on detecting a relationship between age and pain sensitivity response rather than between 
men and women and this might explain the discrepancy. A consensus report on sex/gender differences of pain by found that small sample size was the most important factor contributing to studies failing to detect sex-related effects on pain [22]. Racine et al. [21] systematically reviewed 122 studies on the effect of sex/gender on experimental pain between 1998 and 2008 and concluded a decade of laboratory research had failed to produce consistent findings. However, we found that women had lower sensory detection thresholds to cold and warmth than men in a previous study [16].

\subsection{BMI-Related Pain Sensitivity Response}

The present study found that adults with higher BMI had higher heat pain threshold and tolerance, suggesting decreased pain sensitivity response. This is consistent with previous studies measuring sensitivity to noxious heat stimuli at the waist and abdomen. Tashani et al. [16] found that individuals who were overweight had higher heat pain thresholds than those with normal weight and Price et al. [23] found that individuals who were obese had higher heat pain threshold and heat pain tolerance than normal weight. Interestingly, these studies failed to detect differences in heat pain response according to BMI at other body sites including the hands [16]. or the forehead [23]. Reasons for the discrepancies are not known. The present study found that adults with higher BMI had lower cold detection thresholds and this is consistent with the findings of Tashani et al. [16] Bohnert et al. [24] has suggested that this observation may be explained by stretching of the skin caused by an accumulation of excess fat leading to a reduction in the density of thermoreceptors, which in turn could reduce transmission of thermal stimuli.

\subsection{Strengths and Weaknesses of the Study}

The design of most previous studies was to compare participants dichotomised as young or old regardless of sex/gender. A strength of our study was the inclusion of various age categories, and sex and BMI into our analysis model. Riley et al. [19] suggested that 41 participants per group would be needed to detect differences in pain sensitivity response to noxious stimuli between women and men and higher than used in our study. We calculated sample size based on detecting an association between age and heat pain tolerance rather than differences of pain sensitivity between men and women, but we acknowledge that this may have reduced statistical power in betweengroup comparisons.

We excluded children, adolescents and adults over 55 years of age from our analysis to reduce the influence of developmental physiological processes occurring at early stages of life, including puberty, and to reduce the influence of comorbidity associated with old age $[7,8]$. This meant that we could not determine the effect of old-age (>60 years) on pain sensitivity response. Our sampling strategy attempted to balance ethnic groups between age categories but we were unable to include ethnicity into our analysis model because of small sample sizes within each age category. Ethnicity affects pain sensitivity response with minority groups exhibiting greater sensitivity to laboratory evoked pain compared to the host community [25]. The effect of ethnicity is also evident between different nationalities in their own countries [26], and likely to be the result of a social and cultural response to pain rather than a bio-psychological construct [27].

\subsection{Implications for Researchers, Clinicians or Policymakers}

The findings of this study suggest that age influences pain sensitivity response and needs to be considered when conducting experimental or clinical studies on pain. However, we suspect that age-related variation in pain sensitivity response in adults under 60 years of age will be less than adults over 60 years and therefore, there is a need for a large study of this population.

\section{CONCLUSION}

The findings of this experimental study provide further evidence that pressure pain threshold increases with age and that women have lower thresholds and tolerances to innocuous and noxious thermal stimuli. However, there were no statistically significant interactions between age or sex/gender for any of the other stimulus modalities measured. Future studies on children and adults over 60 years of age are needed.

\section{ETHICS APPROVAL AND CONSENT TO PARTICIPATE}

Ethical approval was given by the Research Ethics Committee at Leeds Beckett University, UK. 


\section{HUMAN AND ANIMAL RIGHTS}

Procedures were in accordance with the 1964 Helsinki declaration and later amendments for ethical standards for studies using human participants.

\section{CONSENT FOR PUBLICATION}

All participants provided written informed consent to participate.

\section{CONFLICT OF INTEREST}

The authors declare no conflict of interest, financial or otherwise.

\section{ACKNOWLEDGEMENTS}

Declared none.

\section{SUPPLEMENTARY MATERIAL}

Supplementary material is available on the publishers Website along with the published article.

\section{REFERENCES}

[1] Gagliese L. Pain and aging: The emergence of a new subfield of pain research. J Pain 2009; 10(4): $343-53$. [http://dx.doi.org/10.1016/j.jpain.2008.10.013] [PMID: 19327641]

[2] Gibson SJ, Farrell M. A review of age differences in the neurophysiology of nociception and the perceptual experience of pain. Clin J Pain 2004; 20(4): 227-39. [http://dx.doi.org/10.1097/00002508-200407000-00004] [PMID: 15218407]

[3] Gibson SJ, Helme RD. Age-related differences in pain perception and report. Clin Geriatr Med 2001; 17(3): 433-456, v-vi. [v-vi.]. [http://dx.doi.org/10.1016/S0749-0690(05)70079-3] [PMID: 11459714]

[4] Lautenbacher S. Experimental approaches in the study of pain in the elderly. Pain Med 2012; 13(Suppl. 2): S44-50. [http://dx.doi.org/10.1111/j.1526-4637.2012.01326.x] [PMID: 22497747]

[5] El Tumi H, Johnson MI, Dantas PBF, Maynard MJ, Tashani OA. Age-related changes in pain sensitivity in healthy humans: A systematic review with meta-analysis. Eur J Pain 2017; 21(6): 955-64. [http://dx.doi.org/10.1002/ejp.1011] [PMID: 28230292]

[6] Lautenbacher S, Peters JH, Heesen M, Scheel J, Kunz M. Age changes in pain perception: A systematic-review and meta-analysis of age effects on pain and tolerance thresholds. Neurosci Biobehav Rev 2017; 75: 104-13. [http://dx.doi.org/10.1016/j.neubiorev.2017.01.039] [PMID: 28159611]

[7] Schofield P, O’Mahony S, Collett B, Potter J. Guidance for the assessment of pain in older adults: A literature review. Br J Nurs 2008; 17(14): 914-8. [http://dx.doi.org/10.12968/bjon.2008.17.14.30659] [PMID: 18935844]

[8] Cole LJ, Farrell MJ, Gibson SJ, Egan GF. Age-related differences in pain sensitivity and regional brain activity evoked by noxious pressure. Neurobiol Aging 2010; 31(3): 494-503. [http://dx.doi.org/10.1016/j.neurobiolaging.2008.04.012] [PMID: 18513833]

[9] Bartley EJ, Fillingim RB. Sex differences in pain: A brief review of clinical and experimental findings. Br J Anaesth 2013; $111(1)$ : 52-8. [http://dx.doi.org/10.1093/bja/aet127] [PMID: 23794645]

[10] Rosen S, Ham B, Mogil JS. Sex differences in neuroimmunity and pain. J Neurosci Res 2017; 95(1-2): 500-8. [http://dx.doi.org/10.1002/jnr.23831] [PMID: 27870397]

[11] Mogil JS. Sex differences in pain and pain inhibition: Multiple explanations of a controversial phenomenon. Nat Rev Neurosci 2012; 13(12): 859-66. [http://dx.doi.org/10.1038/nrn3360] [PMID: 23165262]

[12] Ahmad OB, et al. Age standardization rates: A new WHO standard: Discussion Paper Series: No.31. 2001, World Health Organization.

[13] Rolke R, Magerl W, Campbell KA, et al. Quantitative sensory testing: A comprehensive protocol for clinical trials. Eur J Pain 2006; 10(1): $77-88$. [http://dx.doi.org/10.1016/j.ejpain.2005.02.003] [PMID: 16291301]

[14] Schestatsky P, Stefani LC, Sanches PR, et al. Validation of a Brazilian quantitative sensory testing (QST) device for the diagnosis of small fiber neuropathies. Arq Neuropsiquiatr 2011; 69(6): 943-8. [http://dx.doi.org/10.1590/S0004-282X2011000700019] [PMID: 22297885]

[15] Chesterton LS, Sim J, Wright CC, Foster NE. Interrater reliability of algometry in measuring pressure pain thresholds in healthy humans, using multiple raters. Clin J Pain 2007; 23(9): 760-6. 
[http://dx.doi.org/10.1097/AJP.0b013e318154b6ae] [PMID: 18075402]

[16] Tashani OA, Astita R, Sharp D, Johnson MI. Body mass index and distribution of body fat can influence sensory detection and pain sensitivity. Eur J Pain 2017; 21(7): 1186-96.

[http://dx.doi.org/10.1002/ejp.1019] [PMID: 28263427]

[17] Herr KA, Spratt K, Mobily PR, Richardson G. Pain intensity assessment in older adults: Use of experimental pain to compare psychometric properties and usability of selected pain scales with younger adults. Clin J Pain 2004; 20(4): 207-19. [http://dx.doi.org/10.1097/00002508-200407000-00002] [PMID: 15218405]

[18] Riley JL III, King CD, Wong F, Fillingim RB, Mauderli AP. Lack of endogenous modulation and reduced decay of prolonged heat pain in older adults. Pain 2010; 150(1): 153-60. [http://dx.doi.org/10.1016/j.pain.2010.04.020] [PMID: 20546997]

[19] Riley JL III, Robinson ME, Wise EA, Myers CD, Fillingim RB. Sex differences in the perception of noxious experimental stimuli: A metaanalysis. Pain 1998; 74(2-3): 181-7.

[http://dx.doi.org/10.1016/S0304-3959(97)00199-1] [PMID: 9520232]

[20] Eltumi HG, Tashani H. OA. Effect of age, sex and gender on pain sensitivity: A narrative review.Open Pain J 2017; 10() : 44-55.

[21] Racine M, Tousignant-Laflamme Y, Kloda LA, Dion D, Dupuis G, Choinière M. A systematic literature review of 10 years of research on sex/gender and pain perception - part 2: Do biopsychosocial factors alter pain sensitivity differently in women and men? Pain 2012; 153(3): 619-35.

[http://dx.doi.org/10.1016/j.pain.2011.11.026] [PMID: 22236999]

[22] Greenspan JD, Craft RM, LeResche L, et al. Studying sex and gender differences in pain and analgesia: A consensus report. Pain 2007; 132(Suppl. 1): S26-45. [http://dx.doi.org/10.1016/j.pain.2007.10.014] [PMID: 17964077]

[23] Price RC, Asenjo JF, Christou NV, Backman SB, Schweinhardt P. The role of excess subcutaneous fat in pain and sensory sensitivity in obesity. Eur J Pain 2013; 17(9): 1316-26.

[http://dx.doi.org/10.1002/j.1532-2149.2013.00315.x] [PMID: 23576531]

[24] Bohnert AS, Eisenberg A, Whiteside L, Price A, McCabe SE, Ilgen MA. Prescription opioid use among addictions treatment patients: Nonmedical use for pain relief $v s$. other forms of nonmedical use. Addict Behav 2013; 38(3): 1776-81. [http://dx.doi.org/10.1016/j.addbeh.2012.11.005] [PMID: 23254228]

[25] Rahim-Williams B, Riley JL III, Williams AK, Fillingim RB. A quantitative review of ethnic group differences in experimental pain response: Do biology, psychology, and culture matter? Pain Med 2012; 13(4): 522-40. [http://dx.doi.org/10.1111/j.1526-4637.2012.01336.x] [PMID: 22390201]

[26] Alabas OA, Tashani OA, Johnson MI. Effects of ethnicity and gender role expectations of pain on experimental pain: A cross-cultural study. Eur J Pain 2013; 17(5): 776-86.

[http://dx.doi.org/10.1002/j.1532-2149.2012.00229.x] [PMID: 23070971]

[27] Watson PJ, Latif RK, Rowbotham DJ. Ethnic differences in thermal pain responses: A comparison of South Asian and White British healthy males. Pain 2005; 118(1-2): 194-200.

[http://dx.doi.org/10.1016/j.pain.2005.08.010] [PMID: 16202529]

\section{(C) 2018 El-Tumi et al.}

This is an open access article distributed under the terms of the Creative Commons Attribution 4.0 International Public License (CC-BY 4.0), a copy of which is available at: (https://creativecommons.org/licenses/by/4.0/legalcode). This license permits unrestricted use, distribution, and reproduction in any medium, provided the original author and source are credited. 